\title{
Formability Studies of Automotive Aluminium Alloy Sheet series: A Review
}

\author{
Anitha Lakshmi ${ }^{1}$, Tanya Buddi $^{2}$, Ram Subbiah ${ }^{3}$, Ch. Bandhavi ${ }^{4}$ \\ ${ }^{1,4}$ Assistant Professor, Dept. of Mechanical Engineering, GRIET, Bachupally, Hyderabad, Telangana, India. \\ ${ }^{2,3}$ Associate Professor, Dept. of Mechanical Engineering, GRIET, Bachupally, Hyderabad, Telangana, India.
}

\begin{abstract}
The job of aluminium alloys in car and aircraft industries has been extending fundamentally over the most recent 20 years. Because of their low thickness to weight proportion and high explicit quality, aluminium turned into a solid trade for steel especially for car producing. However, to stamp a convoluted board parts from aluminium sheet is very troublesome explicitly at cold working temperatures where as far as possible are very less. To enhance formability breaking points of aluminium alloy sheet a few procedures are joined by numerous specialists like warm shaping, hot forming, superplastic forming, cold die quench (HFQ) forms and so on. This paper displays a basic study of various procedures utilized to enhance aluminium alloy sheet formability and distinguishing advantages and downsides for each procedure
\end{abstract}

\section{Introduction}

In automobile industry aluminium alloy sheets have an immense interest due to their critical mechanical, tribological and physical properties contrasted with the base alloys. The noteworthy properties are great rigidity and high wear and specific strength, seizure opposition, high firmness, high temperatures quality, better thermal expansion coefficient and enhanced damping limit. A few samples are car bodies, air ship boards, machine bodies, kitchen utensils and refreshment jars. Aluminium alloys have been the principle for airframe materials since they began supplanting wood in the late 1920[1]. Also, it is perfect for the development of little recreation boats, extravagance vessels, workboats, angling vessels $[2,4]$. The use of aluminium alloy in the car business has expanded over $80 \%$ in the previous 5 years. In 1996 an aggregate of $110 \mathrm{~kg}$ of aluminium composites were utilized in a vehicle. This amount is predicted to increment to 250 or $340 \mathrm{~kg}$ paying little respect to the basic applications [3]. The sheet-metal forming is a basic and proficient assembling process. High efficiency and low creation cost can be normal for business scale generation.

Forming limit graph (FLD) is a standout amongst the most helpful diagram to assess the sheet metals formability, which was initially for the negative minor strain area proposed by Keeler, and afterward positive minor strain region was developed by Goodwin. For such a significant number of years forming limit (FLC) curve have been utilized so as to survey the sheet material formability. They have been connected in the structure phase of devices, utilizing the finite element method as simulation tool which is broadly utilized in a production area. Planar biaxial elastic test machines have likewise been utilized to decide FLDs for metallic materials since strain path can be controlled precisely and the impact of the friction can be maintained a strategic distance from forming. Test techniques to get FLDs are of tedious and expensive, particularly testing at hoisted temperatures. Accordingly, numerous theoretical and numerical techniques have been proposed and created to anticipate the formability of sheet metals.

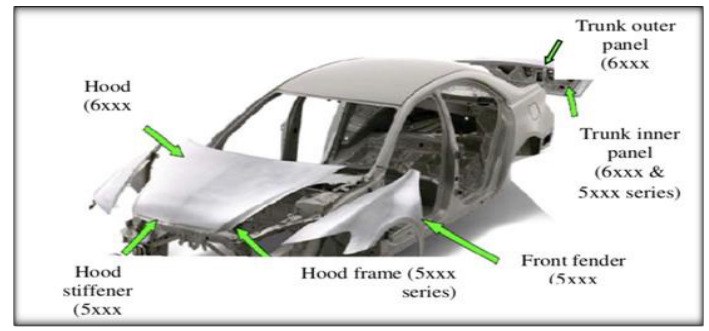

Fig.1. Aluminium alloys applications in the Automotive components of a typical passenger car [1]

\section{Formability of $1 \times x x$ series aluminium alloy}

This review has been made based on different tensile, formability tests, and finite element simulation done by the different researchers for foreseeing formability behaviour of aluminium alloy sheet. Reza ESMAEILIZADEH et al [5] led a few tensile tests on AA1200 tests at various angles, with respect to the moving course (Rolling Direction), to decide the required various AA1200 alloy mechanical properties for simulation. Stretch forming test was led by cutting

\footnotetext{
* Corresponding author: anitha.akkireddy@gmail.com
} 
samples from the tempered (at temp of $350^{\circ} \mathrm{C}$ for $5 \mathrm{~min}$ ) and un strengthened AA1200 material with the measurements of $100 \times 100 \times 2 \mathrm{~mm}$. All tests are done under room temperature. Their outcomes demonstrate that the anisotropic plastic behavior of rolled sheet is existed even in the wake of toughening and recrystallization tasks.

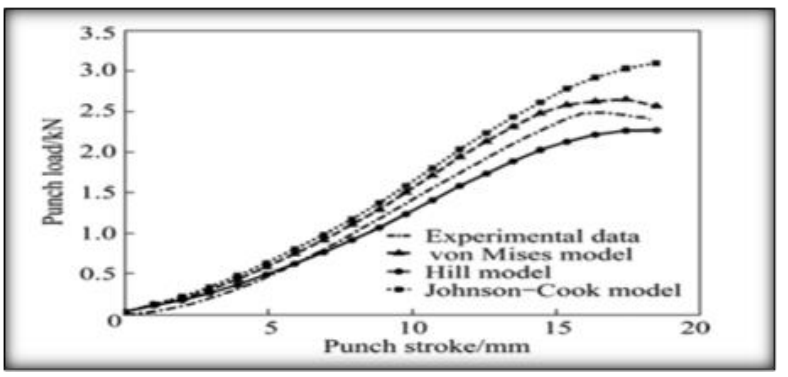

Fig.2. Comparison of experimental and simulation works [5]

They utilized Von mises, Johnson cook and Hill criterion material models for characterizing the plastic behavior of the model. The force curve of exploratory stretch forming tests are contrasted with the three models and found that experimental determined curve results are in great assertion compared with the Hill standard model as appeared in Fig.2. After stretch forming tests, the measures of punch powers utilized were plotted versus displacements to approve the simulation results of this test. Strengthening activities like annealing and recrystallization process don't take out the anisotropic plastic conduct of the rolled sheet, and found the utilization of isotropic yield foundation for anisotropic materials, has nothing more than a bad memory results in finite element simulation work.

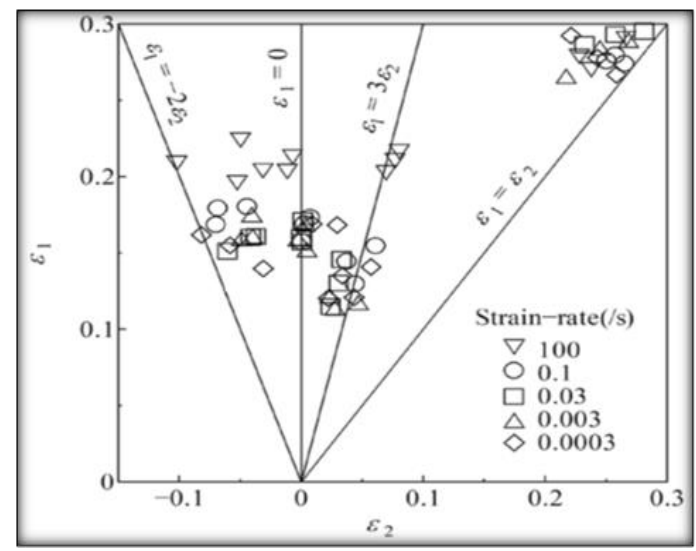

Fig.3. Forming limit strain A1050 [7]

Thirunagari srinivas et. al. [6] has conveyed warm deep drawing process for parametric optimization of 1100 aluminium alloy. Amid this procedure they have taken parameters like thickness of blank, temperature, friction coefficient and strain rate. Here Erichsen deep drawing test was led to study the formation of wrinkles in the cups. Utilizing D-Form programming test results are analyzed. In this advancement procedure orthogonal array L9 is utilized and found sheet thickness play as a noteworthy parameter for powerful strain and volume of the cup. Here damage of the cups was less with thick sheets and the damage is more at high coefficient of friction, strains-rate and temperature. (Minoru Yamashita et al $[7,8]$ ) led formability tests to examine on impact of strain-rate on forming limit in biaxial extending of aluminium A1050 sheet. Here they directed stretch forming test by Marciniak and Kuczynski M-K Method and test esteems taken as rapid around 100/s, in the low-speed from 0.0003 to $0.1 / \mathrm{s}$. From the Fig.3 diagram demonstrates that Limit strain of A1050 in rapid test was strikingly bigger than those in low-speed test with the exception of equibiaxial stretching. The strain was comparable in low-speed range.

\section{Formability of 2xxx series aluminium alloy}

Wennan Yuan, et al [9] has directed tensile tests to obtain the properties of material, just as to calibrate hardening model for the aluminium alloy 2021. Here 1.0 $\mathrm{mm}$ measure sheet was utilized and the material is set to $0^{\circ}, 45^{\circ}$ and $90^{\circ}$ as for the moving course. The numerical model Nakazima test was led, that is more, finite element simulation is accustomed to foreseeing the FLC. The Fig. 4 demonstrates red segment is necked component and close is neighboring component. The diagram demonstrates uniform twisting of the necked component and its nearby component. Strains vacillate around zero inside a little range, and began to rise pointedly at the necking procedure, correspondingly the punch force started to decrease. Furthermore, they found at 0.15 rubbing coefficient the strain dispersion is uniform and break commencement is great.

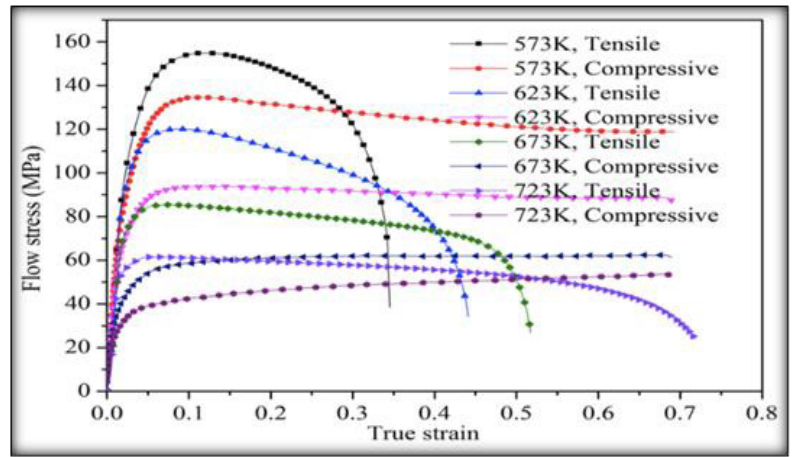

Fig.4. The Stress-strain curves comes by compressive and Tensile tests at starting strain rate of $0.1 \mathrm{~s}^{-1}$ [9]

\section{Formability of $3 x x x$ series aluminium alloy}

An experimental and numerical investigation of the isothermal and non-isothermal warm formability of an AA3003 aluminium alloy alloy sheet is conveyed by Reza Bagheriasl et al [10].

Limit doming height (LDH) tests are utilized for deciding Forming limit charts at room temperature, $100^{\circ} \mathrm{C}, 200^{\circ} \mathrm{C}, 250^{\circ} \mathrm{C}$, and $300^{\circ} \mathrm{C}$ and strain-rates $(0.003$, 0.018 , and $\left.0.1 \mathrm{~s}^{-1}\right)$ are considered for creating FLD. From Fig 5(a) it is seen that formability (limiting strains) expanded impressively with expanding test temperature, while rate impacts are unimportant inside the scope of speed, however, required extra gear for executing a fast 
camera set up with the DIC framework, and shaping velocities utilized in these trials. They finished up higher rate impacts might be seen by expanding the forming as in this manner outside the extent of their investigation.

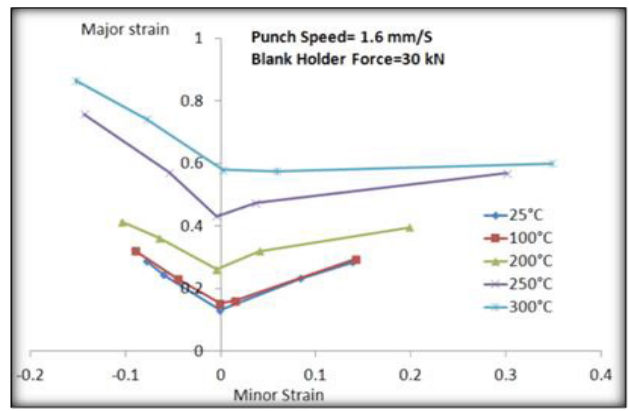

Fig.5. FLD of $0.5 \mathrm{~mm}$ thick AA3003 at $1.6 \mathrm{~mm} / \mathrm{s}$ punch speed [10]

\section{Formability of $4 x x x$ series aluminium alloy}

Swadesh Kumar Singh et al [11] dealt with Characterization and formability of aluminium IS 737 40800 series material at raised temperatures. The material is drawn at raised temperature and its formability was explored in warm condition. Here the predefined test rig is utilized to make extend shaping.cups were drawn at room temperature, $200{ }^{\circ} \mathrm{C}$ and $350{ }^{0} \mathrm{C}$ where punch load and displacement information were recorded. The sensitivity index value is determined by jump test. The outcomes appear with expanding temperature because of lessening in the mean flow stresses formability increments. Drawn cups what's more, it was additionally found there is uniform thickness variety for a similar draw proportion at raised temperature as appeared in Fig 6. Degree of necking diminishes because of lessening in the punch load amid forming.
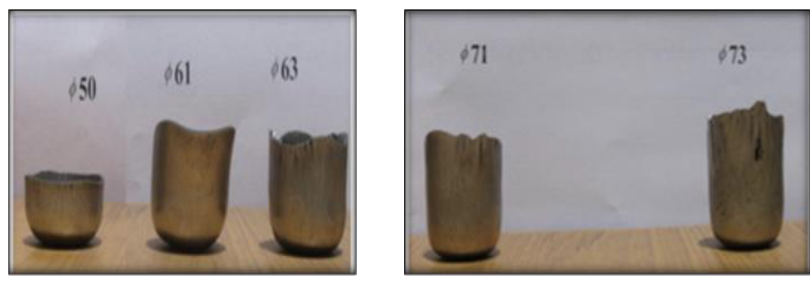

Fig.6. Al IS 737 alloy at $200^{\circ} \mathrm{C}$ Drawn cups (b) Al IS 737 alloy at $350^{\circ} \mathrm{C}[11]$

\section{Formability of $5 x x x$ series aluminium alloy}

Fitsum T. Feyissa et al [12] worked on formability of cryorolled Al sheets. Hybrid breed handling course is created to improve quality just as formability of AA5083alloy by warm forming. Here the $5 \mathrm{~mm}$ thickness of sheet is solutionized at $530^{\circ} \mathrm{C}$ pursued by water extinguishing. These sheets were cryrolled to $1 \mathrm{~mm}$ thickness with $80 \%$ thickness decrease. Formability in biaxial stretch forming (limiting dome height) of these sheets was described at room temperature and lifted temperatures $\left(200^{\circ} \mathrm{Centigrade}, 250^{\circ} \mathrm{C}\right.$ and $\left.300^{\circ} \mathrm{C}\right)$. The Fig 7 demonstrates strain calculation at various temperature and distance from pole. Here the peak major and minor strains expanded with increment in temperature. The outcomes appear, there is enhancement in formability of cryorolled 5083 sheets in biaxial streching mode (Limiting Dome Height) at hoisted temperatures going from $200^{\circ} \mathrm{C}$ to $300^{\circ} \mathrm{C}$ contrasted with room temperature.

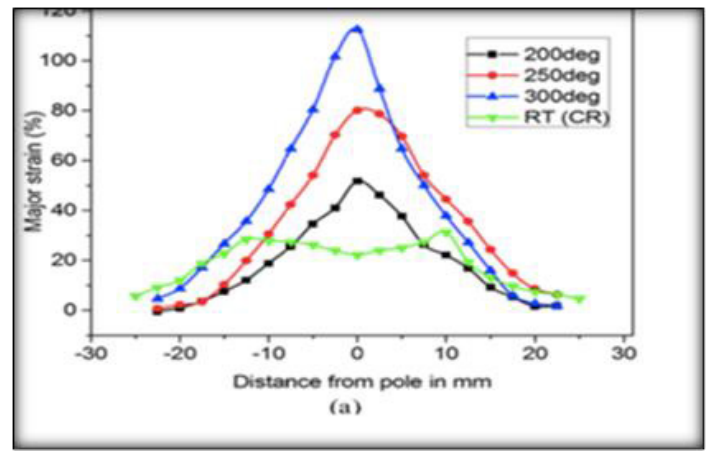

Fig.7. Represents strain distribution of AA5083 alloy at warm forming temperatures [12]

The numerical M-K demonstrate is produced considering the groove orientation has very much anticipated the limit strain paths of the alloy as appeared in Fig8, It was discovered the pre-strain improves the formability in biaxial stretching state, while results decline marginally in as far as possible in opposite strain states. The outcomes demonstrate that the stress state rotation brought about by the strain path change goes through the stress state at plane strain state, it expands the significant strain increase proportion and therefore influences the forecast aftereffects of the M-K theory.

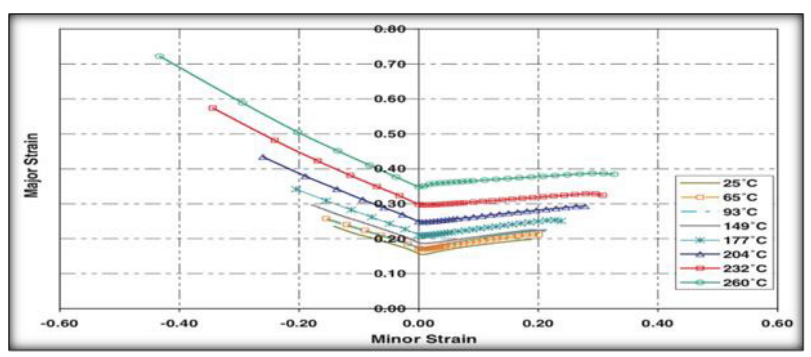

Fig.8. The forming limits in strain space and stress space [12]

Reenactment results were contrasted and experimental data at a few lifted temperatures to assess the exactness of the UMAT's capacity to foresee both forming created models utilizing anisotropic yield capacity, and Voce hardening law at a few raised temperatures. Barlat's anisotropic model for the two alloy materials at a few hoisted behaviour and failure locations. (LDH) tests are directed by utilizing changed Interlaken 30-ton double activity servo press. As observed from the Fig 9. expanding temperature adequately raises forming limiting curves, They found at temperature $149^{\circ} \mathrm{C}(300$ 
${ }^{\circ} \mathrm{F}$ ) are failure punch profundity and failure areas of experimental and completely coupled thermomechanical simulation of pure stretching of AA5182-O. at a temperature of $177^{\circ} \mathrm{C}\left(350{ }^{\circ} \mathrm{F}\right)$ shows the failure depth of punch and failure areas of completely coupled thermo-mechanical simulation of pure stretch of AA5754-O at a temperature of $149^{\circ} \mathrm{C}$.

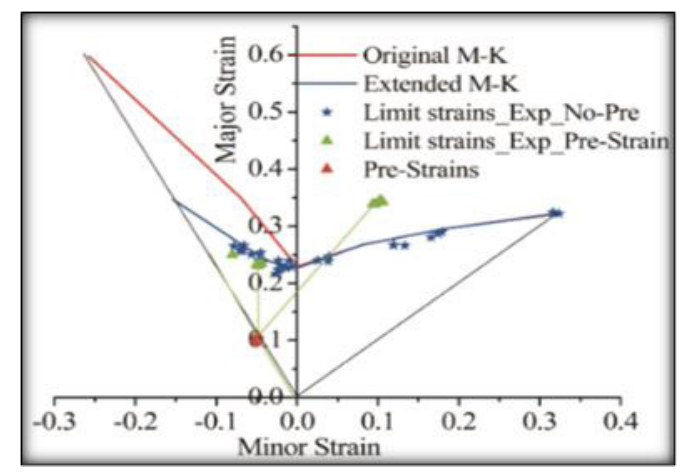

Fig.9. FLD (e-FLDs) for AA5182-O based on the M-K model and Barlat's YLD200-2d [12]

In this work results indicates exactness of the Barlat's anisotropic YLD2000-2d yield work at the room temperature has just been altogether checked by numerous analysts. Along these lines, to expect comparative execution at hoisted temperature isn't irrational

\section{Formability of $6 x x x$ series aluminium alloy}

Xi Luan, et al [13] studies on Formability limit charts (FLDs) of AA6082 at hot and warm stamping conditions by utilizing an specially structured test rig. The tests were done at different temperatures from $300^{\circ} \mathrm{Centigrade}$ to $450^{\circ} \mathrm{C}$ and forming speeds extending from $75 \mathrm{~mm} / \mathrm{s}$ to $400 \mathrm{~mm} / \mathrm{s}$. FLD at various temperature demonstrates the significant strain enhanced by roughly $25 \%$ from $300^{\circ} \mathrm{C}$ to $400^{\circ} \mathrm{C}$. Under plain strain condition enhancement, the major strain was over $40 \%$ over a similar temperature extend. Formability increments with decreasing forming speed, despite the fact that the thing that matters was minor between the forming paces of $250 \mathrm{~mm} / \mathrm{s}$ and 400 $\mathrm{mm} / \mathrm{s}$. At that point the outcomes demonstrate the strain rate affectability of the material is upgraded at lifted temperatures and lower forming speeds. They discovered formability of AA6082-6 sheet metal expanded by $38.9 \%$ when the forming temperature are expanded from $300^{\circ} \mathrm{C}$ to $450^{\circ} \mathrm{C}$ at a speed of $250 \mathrm{~mm} / \mathrm{s}$ in terms of limit major strain and expanded by $42.4 \%$ when the forming speed are diminished from $400 \mathrm{~mm} / \mathrm{s}$ to $75 \mathrm{~mm} / \mathrm{s}$ at a temperature of $400^{\circ} \mathrm{C}$. It was checked that hot stepping is a promising innovation for assembling complex-molded segments.

Anoop Kumar[14] considers impact of sheet metal thickness on formability of aluminium alloy 6061 . In this work diverse thickness samples are chosen to perform formability test utilizing distinctive tribological conditions. It is assessed that the formability of the material shifts on thickness variety under greased up conditions. The outcomes show thicker sheets displayed better formability with in the example of various thickness chose in the examination. The lubricant graphite has more effect on the formability of aluminium alloy in contrast with other lubricant chose in the investigation.

\section{Formability of $7 x x x$ series aluminium alloy}

M.KUMAR, et al [15] Conducts Investigations on warm forming of AW-7020-T6 sheet. They directed warm tensile test, swift cupping and cross die deep drawing tests at temperatures somewhere in the range of 150 and $250^{\circ} \mathrm{C}$. The Swift cupping tests were performed in an Errichsen Model 142-40-Basic Universal metal testing machine.

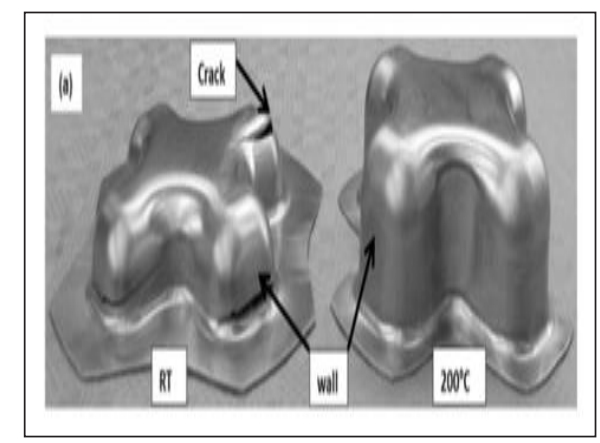

Fig.10 LDR and LDD values at elevated temperature [13]

The above figure uncovers at $200^{\circ} \mathrm{C}$ the deep drawn segment is great however at room temperature breaks are obvious. In Fig 10 the drawing ratio increment with expanding temperature from $170^{\circ} \mathrm{C}$ to $250^{\circ} \mathrm{C}$. Essentially, the limiting drawing depth from cross-die on tests likewise increments significantly with expanding temperature between $150^{\circ} \mathrm{C}$ to $200^{\circ} \mathrm{C}$.

The tensile test outcomes demonstrate that the AW7020-T6 Yield quality and Ultimate tensile strength decline with expanding temperature. Also, true break strain, LDR and LDD increment with expanding temperature over $150^{\circ} \mathrm{C}$ because of dynamic recuperation and disintegration of hastens. Yanli Song et al [16] works on farming behavior of aluminium alloy dainty walled chamber parts by servo hot stamping. Hot stamping was set up dependent on FE simulation programming $\mathrm{ABAQUS}$ and the stamping temperatures are taken between $20^{\circ} \mathrm{C}$ to $475^{\circ} \mathrm{C}$. They set beginning forming hot temperature of blank was $420^{\circ} \mathrm{C}$ and the underlying temperatures of the punch and die were $25^{\circ} \mathrm{C}$. Contrasted with the case with the motion curve 1 , the estimations of the most extreme FLD and the greatest diminishing rate are individually decreased by about $48 \%$ and $29 \%$ with the servo motion method of V2, V3 and V4. Along these lines, it very well may be reasoned that the AA7075-T6 formability of blank is enhanced when the stepping speed is restricted in the territory 
between motion curve number 2 and the motion curve number 4.

\section{Formability of $6 x x x$ series aluminium alloy}

V.P. Srinivasan et al [17] make an examination on formability of aluminium 8011 alloy by Using Finite Element Method. Erichsen cup test is completed and reenacted utilizing axisymmetric finite element technique. The impacts of sheet thickness and frictional condition between the punch and sheet on formability is anticipated and contrasted and the test aftereffects of the Erichsen test. Uniaxial strain tests were completed in the of $00,450,900$, to the moving bearing. Sheet with a thickness of $1 \mathrm{~mm}, 1.5 \mathrm{~mm}, 2 \mathrm{~mm}$. are tried utilizing two kinds of oil (1) dry $(\mu=0.3)(2)$ oil by oil $(\mu=0.21)$ in the test. It results better formability in expanding sheet thickness and utilizing lubrication indicates.

Lakshmi, A. Anitha, et al., has worked on formability of ASS 304 sheets for automotive applications at elevated temperatures where formability is analysed in single uniaxial load direction, anisotropy, strain rate sensitivity and mechanical properties are evaluated [18-20]. Harshini, Dharanikota, et al., worked on comparative study on mechanical properties, formability of ASS316 $\mathrm{L}$ at elevated and sub-zero temperatures [21-23], AU Haq demonstrates the evaluation and optimization of material properties of ASS $316 \mathrm{~L}$ at elevated temperatures using Response Surface Methodology [24], B Dharavath et al compares the study of ASS 316L on formability at room temperature and super plastic region [25]. S Kosaraju et al demonstrate the evaluation and characterization of ASS316L at sub-zero temperature [26]. KVD Rajesh et al finds the microstructural and corrosion resistance study on plasma arc welded joints of AISI 304 and AISI 316. Subbiah, Ram, et al worked-on wear behaviour of Al-2014 Alloy Coated by varying processes [27]. Reddy, D. Mahesh, has worked on formability of $\mathrm{Al} 8011$ alloy sheets under uniaxial test condition [28]. Singh, Swadesh Kumar etal., worked on Automotive steels using optimization tools like Artificial Neural Networks, support vector regression and simulation tools like LSDyna for predicting formability and defects [29-32].

\section{Conclusions:}

Literature review has been made on the basis of various tensile and formability tests, both experimental, finite element simulation done by the various scholars for predicting formability behaviour of aluminium alloy sheet in this paper. Majority of tests are conducted at room temperature for the prediction of material forming limits compared to predict formability at high temperatures. There is a need to investigate the occurrence and significance of formability of aluminium alloys from engineering perspective. For predicting FLD on $\mathrm{Al}$ alloy sheets about influence on the final product properties such as strength, hardness, formability and durability. Among all series of $\mathrm{Al}$ alloy sheets $\mathrm{Al} 8011$ is selected for further investigation. Fe and $\mathrm{Si}$ content in this series plays major role in formability parameters, few peoples are done forming tests by varying these two elements on the alloy. This material is most widely used in aerospace industries due to their low weight and high strength properties. Al 8011 is the strongest material out of all the series. Further work is being carried on material characterization and hot forming of $\mathrm{Al} 8011$ alloy sheets at varying temperature, thickness, and strain rate to find effect on the formability of, the temperature upto $450{ }^{0} \mathrm{C}, 1.2 \mathrm{~mm}$ thickness and 0.001 strain rate. Prediction on hot forming of $\mathrm{Al} 8011$ alloy with $\mathrm{FE}$ $0.35 \%$, SI $0.1 \%$ content.at temperature up to $450{ }^{0} \mathrm{C}$, $1.2 \mathrm{~mm}$ thickness and $0.001 \mathrm{~s}^{-1}$. This study helps to predict the formability limit of Al 8011 alloy used in construction and aerospace industries.

\section{References}

1. Campbell, Flake C., ed. Lightweight materials: understanding the basics. ASM International, 2012.

2. P. Rambabu, N. Eswara Prasad, V.V. Kutumbarao and R.J.H. Wanhill. 2017

3. AZO materials website: https://www.azom.com/article.aspx?ArticleID=419 3

4. Esmaeilizadeh, Reza, et al. Trans. Nonferrous Met. Soc. China 24 (2014): 484-490.

5. Srinivas, Thirunagari, and A. Chennakesava Reddy. International Journal of Scientific \& Engineering Research 6.4 (2015): 425-433.

6. Yamashita, Minoru, Makoto Nikawa, and Takayoshi Kuroda. Procedia Manufacturing 15 (2018): 877-883.

7. Dursun, Tolga, and Costas Soutis. Materials \& Design (1980-2015) 56 (2014): 862-871.

8. Rajagiri A, MN Sandhya, Nawaz S, Suresh Kumar T, E3S Web of Conferences 8701004 (2019)

9. Cavaliere, P. Journal of Light Metals 2.4 (2002): 247-252.

10. Singh, Swadesh Kumar, et al. Characterization and formability of aluminium IS 73740800 grade material at elevated temperature.

11. Satish, D. Raja, Fitsum T. Feyissa, and D. Ravi Kumar. International Journal of Materials, Mechanics and Manufacturing 6.2 (2018): 123-126.

12. Ma, B. L., et al. International Journal of Mechanical Sciences 142 (2018): 420-431.

13. Barnwal, Vivek Kumar, et al. Materials Science and Engineering: A 679 (2017): 56-65.

14. Polak, Sławomir, et al Procedia engineering 207 (2017): 2399-2404.

15. Kumar, M., N. Sotirov, and C. M. Chimani. Journal of Materials Processing Technology 214.8 (2014): 1769-1776.

16. Song, Yanli, et al., Procedia engineering 207 (2017): 741-746.

17. Yogeswara Reddy B, Srinivas Rao J, Suresh Kumar T, Nagarjuna A, Int. J. of Inn Tech and Exp Engg., 8.11, (2019): 1194-1198.

18. Lakshmi, A. Anitha, et al. Materials Today: Proceedings 4.2 (2017): 946-956. 
19. Lakshmi, A. Anitha, et al. Materials Today: Proceedings 5.2 (2018): 3704-3712.

20. Harshini, Dharanikota, et al Materials Today: Proceedings 19 (2019): 767-771.

21. Lakshmi, A. Anitha, Ch Srinivasa Rao, and Tanya Buddi. Materials Today: Proceedings 18 (2019): 2814-2822.

22. Lakshmi, A. Anitha, et al Int. J. Mech. Eng. Technol. (IJMET) 9.12 (2018): 403-407.

23. Subbiah, Ram, et al., Materials Today: Proceedings 18 (2019): 5151-5157.

24. Reddy, D. Mahesh, A. Anitha Lakshmi, and Ahsan ul Haq. Materials Today: Proceedings 19 (2019): 366-371.

25. Singh, Swadesh Kumar, Amrit Dixit, and D. Ravi Kumar. The International Journal of Advanced Manufacturing Technology 38.1-2 (2008): 32-37.

26. Singh, Swadesh Kumar, Amit Kumar Gupta, and K. Mahesh. CIRP Journal of Manufacturing Science and Technology 3.1 (2010): 73-79.

27. Singh, Swadesh Kumar, and Amit Kumar Gupta. CIRP Journal of manufacturing Science and Technology 3.1 (2010): 66-72.

28. AU Haq, AK Kavit, T Rao, Tanya Buddi, D Baloji, K Satyanarayana, SK Singh, Elsevier Materials Today: Proceedings 18, (2019), 4589-4597.

29. B Dharavath, A ul Haq, Tanya Buddi, SK Singh, MT Naik (2020), Advances in Materials and Processing Technologies, Taylor \& Francis 1-12, DOI: $10.1080 / 2374068 X .2020 .1728648$, ISSN: 2374-0698

30. S Kosaraju, SK Singh, Tanya Buddi, A Kalluri, , Advances in Materials and Processing Technologies, Taylor \& Francis,1-11, (2020) DOI: $10.1080 / 2374068 X .2020 .1728650$, ISSN: 2374-0698.

31. KVD Rajesh, Tanya Buddi, PR Kanth, K Satyanarayana, Advances in Materials and Processing Technologies, Taylor \& Francis, 1-17, DOI: $\quad 10.1080 / 2374068 X .2020 .1732158$, ISSN: 2374-0698, (2020).

32. AA Lakshmi, CS Rao, Tanya Buddi., Modern Manufacturing Processes 1st Edition, Elsevier, Chapter 5, (2020). 